\title{
Standard or hypofractionated radiotherapy in the postoperative treatment of breast cancer: a retrospective analysis of acute skin toxicity and dose inhomogeneities
}

\author{
Grazia Tortorelli, Luana Di Murro, Rosaria Barbarino, Sara Cicchetti, Daniela di Cristino, Maria Daniela Falco, \\ Dahlia Fedele, Gianluca Ingrosso, Dania Janniello, Pasquale Morelli, Alessandra Murgia, Elisabetta Ponti, \\ Sara Terenzi", Barbara Tolu and Riccardo Santoni
}

\begin{abstract}
Background: To identify predictive factors of radiation-induced skin toxicity in breast cancer patients by the analysis of dosimetric and clinical factors.

Methods: 339 patients treated between January 2007 and December 2010 are included in the present analysis. Whole breast irradiation was delivered with Conventional Fractionation (CF) (50Gy, 2.0/day, 25 fractions) and moderate Hypofractionated Schedule (HS) (44Gy, 2.75Gy/day, 16 fractions) followed by tumour bed boost. The impact of patient clinical features, systemic treatments and, in particular, dose inhomogeneities on the occurrence of different levels of skin reaction has been retrospectively evaluated.
\end{abstract}

Results: G2 and G3 acute skin toxicity were $42 \%$ and 13\% in CF patients and 30\% and 7.5\% in HS patients respectively. The retrieval and revaluation of 200 treatment plans showed a strong correlation between areas close to the skin surface, with inhomogeneities $>107 \%$ of the prescribed dose, and the desquamation areas as described in the clinical records.

Conclusions: In our experience dose inhomogeneity underneath G2 - G3 skin reactions seems to be the most important predictor for acute skin damage and in these patients more complex treatment techniques should be considered to avoid skin damage. Genetic polymorphisms too have to be investigated as possible promising candidates for predicting acute skin reactions.

\section{Background}

Radiation Therapy (RT) has gained an established role in the treatment of breast cancer either as chest wall irradiation for high risk patients after modified radical mastectomy, or as whole breast irradiation for patients after a breast conserving surgery (BCS). The challenge now is to minimise the morbidity caused by treatment without losing its efficacy and to select patients at risk of developing skin toxicity who deserve more complex treatment techniques able to reduce this problem. Acute and

\footnotetext{
* Correspondence: sara_terenzi@faswebnet.it

Department of Diagnostic Imaging, Molecular Imaging, Interventional Radiology and Radiotherapy, Tor Vergata University General Hospital, Viale Oxford 81, Rome 00133, Italy
}

\section{() Biomed Central}

chronic toxicities have been reported in patients after breast or chest wall RT $[1,2]$. Postoperative RT for breast cancer patients is delivered using conventional tangential fields with dose inhomogeneities resulting in an excess irradiation of breast tissue. Three-dimensional conformal Radiation Therapy (3D-CRT), IMRT and Tomotherapy are associated with relatively lower risks of toxicity compared with 2D technique [3,4]. Skin toxicity can lead to temporary or permanent cessation of treatment, pain, occasionally systemic infection, and may cause permanent skin changes. This problem may probably be reduced improving dose conformity and dose homogeneity within the irradiated area and in close proximity of the skin surface in spite of the fact that complex techniques as 
IMRT are time consuming and more expensive. Few studies [5] have addressed this item, but off-axis dose inhomogeneities have rarely been considered although it has been suggested by some Authors [6].

With the limits of retrospective studies, some data have suggested that dose inhomogeneties ( $\mathrm{V}>107 \%)$ was a significant predictor of RT-induced skin toxicity on the occurrence of severe skin reactions $[7,8]$.

The aim of our analysis is to try to relate "hot spot" volumes, sites and amount of dose inhomogeneities to skin toxicity in a set of patients who underwent 3D conformal irradiation whose 3D treatment plans were retrieved and revaluated to calculate the volumes of Planning Target Volume and Treated Volume receiving more than $107 \%$ of the prescribed dose.

\section{Methods}

\section{Characteristics of patients and data collection}

Between January 2007 and December 2010, 339 evaluable patients for the present analysis, with histological confirmed early breast cancer (pT1-2, pN0-1), were referred, for post-operative treatment after breast conservative surgery, to our Radiation Therapy Unit. The main clinical features of these patients and of the tumours are reported in the Table 1 . All of the patients provided an informed consent for breast irradiation. Patients who received prior breast irradiation, presented bilateral breast cancer, affected by seromas, wound infection, connective tissue disorders were excluded by the present evaluation.

All of these patients underwent a clinical examination before irradiation, weekly during the treatment course and one week after the end of treatment, every month for three months and at regular time intervals (every three months) afterwards. One hundred and twenty six patients received adjuvant chemotherapy after surgery and before RT. Hormone therapy (tamoxifen or aromatase inhibitors) were prescribed to 247 patients. Written informed consent was obtained from the patients for the purpose of this report as well as it concerns any accompanying image. Our Institutional Ethic Committee (Comitato Etico Indipendente, Fondazione Policlinico Tor Vergata, Roma) approved this study (protocol number 104/12).

\section{Total dose and fractionation}

Whole breast irradiation was delivered with Conventional Fractionation (CF) in 141 patients (50 Gy, 2 Gy/ day in 25 fractions) and moderate Hypofractionated Schedule (HS) in 198 ones (44 Gy, 2.75 Gy/day in 16 fractions) followed by an electron tumour bed boost (10-16 Gy, 2 Gy/day in 5-8 fractions or 9-15 Gy, 3 Gy/ day in 3-5 fractions).

\section{Biological equivalent dose}

The biologically effective doses (BED) were calculated assuming 4 Gy $\alpha / \beta$ ratio (tumour control), 10 Gy (acute responding normal tissues) [9].

Differences in fractionation and overall treatment time were taken into account using the following formula: $\mathrm{BED}=(\boldsymbol{n} \cdot \boldsymbol{d})(\boldsymbol{1}+\boldsymbol{d} /(\boldsymbol{\alpha} / \boldsymbol{\beta}))-(\ln 2 /(\alpha \cdot T p k) \cdot(\boldsymbol{T}-\boldsymbol{T} \boldsymbol{k})$.

Only for the CF and for tumour control the time factor (2nd addendum in the above equation) has been taken into account. BEDs for HS was calculated assuming zero as time factor [9]. Description of the parameters used in the above formula are detailed in the Appendix.

\section{Localization and planning}

Planning CT scans (5 mm slice thickness) from the level of the larynx to the upper abdomen, including both lungs, were obtained in the supine or prone position depending on patient tolerance and anatomy. Women in supine set-up were positioned using a "wing-board" (BIONIX Development Corporation, Toledo, Ohio) with both arms raised above their head. Prone patients were positioned using a commercially available immobilization device (CIVCO, Orange City, USA).

CT data were transferred to Precise Plan ${ }^{\circledR}$ (Elekta, Crawley, United Kingdom). Clinical Target Volume (CTV) included whole breast tissue and was expanded by $10 \mathrm{~mm}$, but within $5 \mathrm{~mm}$ from the skin surface, to create the planned target volume (PTV). Organs at Risk (OARs), lung and heart, were contoured according to the 50 and 62 International Commission on Radiations Units and Measurements Reports Recommendations (ICRU) [10,11]. 3D-CRT plans with opposing tangential beams were planned to cover the PTV and a multi-leaf collimator (MLC) was used, when necessary, to minimize the dose delivered to the OARs. Beam energy was $6 \mathrm{MV}$; mixed energies (6 MV-10 MV) were occasionally used in larger breasts. Wedges were used in almost all of the patients to provide a homogenous PTV dose (95\% of 50 Gy and 44 Gy for the CF and HS groups respectively). For each patient, dose-volume histograms (DVHs) for the target and OARs were obtained. Boost doses were delivering using a 6-12 MeV electron fields. All patients were treated using the Elekta Precise ${ }^{\circledR}$ Accelerator (Elekta, Crawley, United Kingdom).

\section{Assessment of acute skin toxicity}

Toxicity was described as the maximum reported acute toxicity, either during or after completion of RT, as described in the clinical records. Clinically evident skin reactions (G2 - G3) were assessed using the RTOG Acute Morbidity Scale defining grade G2 as tender or bright erythema, patchy moist desquamation/moderate oedema, 
Table 1 Main features of the 339 reported patients

\begin{tabular}{|c|c|c|c|c|}
\hline & Total patients (\%) & CF Patients (\%) & HS Patients (\%) & P Value \\
\hline No. & 339 & $141(41.59)$ & $198(58.41)$ & \\
\hline Mean age (range) & $60(22-86)$ & $52(22-79)$ & $62.5(38-86)$ & $<0.001$ \\
\hline Histology & & & & NS \\
\hline ILC & $30(8.8)$ & $12(8.5)$ & $18(9.1)$ & \\
\hline IDC & $299(88.2)$ & $126(89.4)$ & $173(87.4)$ & \\
\hline Intraductal & $10(3)$ & $3(21)$ & $7(3.5)$ & \\
\hline T stage & & & & NS \\
\hline $\mathrm{T} 1$ & $293(86.4)$ & $121(85.8)$ & $172(86.7)$ & \\
\hline $\mathrm{T} 2$ & $46(13.6)$ & $20(14.2)$ & $26(13.3)$ & \\
\hline N stage & & & & NS \\
\hline Nx & $21(6,3)$ & $8(5,7)$ & $13(6,5)$ & \\
\hline No & $251(74)$ & $93(65.9)$ & $158(79.8)$ & \\
\hline N1 & $67(19.7)$ & $32(22.6)$ & 35 (17.6) & \\
\hline Grading (Bloom Richardson's scale) & & & & NS \\
\hline G1 & $60(17.7)$ & $22(15.6)$ & $38(19.2)$ & \\
\hline G2 & $131(38.6)$ & $58(41.1)$ & $73(36.8)$ & \\
\hline G3 & 79 (23.3) & $36(25.5)$ & $43(21.7)$ & \\
\hline NA & 69 (20.4) & $25(17.8)$ & $44(22.3)$ & \\
\hline$\underline{\text { Surgical margins }}$ & & & & NS \\
\hline Negative & $295(87)$ & $124(87.9)$ & $171(86.4)$ & \\
\hline Positive & $5(1.5)$ & $2(1.4)$ & $3(1.5)$ & \\
\hline Close $(<2 \mathrm{~mm})$ & $27(8)$ & $10(7.1)$ & $17(8.6)$ & \\
\hline Tangents & $12(3.5)$ & $5(3.6)$ & $7(3.5)$ & \\
\hline \multicolumn{5}{|l|}{ Breast Volume } \\
\hline Average cc & 718.7 & 684 & 725.4 & NS \\
\hline (range) & $(188.6-2036.7)$ & (188.6-1899.9) & (193.3-2036.7) & \\
\hline \multicolumn{5}{|l|}{ Chemotherapy } \\
\hline Yes & $126(37.2)$ & $68(48.2 \%)$ & $58(29.3 \%)$ & \\
\hline No & $211(62.2 \%)$ & 72 (51.1\%) & 139 (70.2\%) & 0.008 \\
\hline NA & $2(0.6 \%)$ & $1(0.7 \%)$ & $1(0.5 \%)$ & \\
\hline \multicolumn{5}{|l|}{$\underline{\text { Hormone therapy }}$} \\
\hline Yes & $247(72.8)$ & $101(71.6)$ & $146(73.7)$ & NS \\
\hline No & $74(21.8)$ & $34(24.1)$ & $40(20,2)$ & \\
\hline NA & $18(5.4)$ & $6(4.3)$ & $12(6.1)$ & \\
\hline \multicolumn{5}{|l|}{ Trastuzumab } \\
\hline Yes & $17(5)$ & $7(5)$ & $10(5)$ & NS \\
\hline No & 327 (95) & $134(95)$ & $188(95)$ & \\
\hline
\end{tabular}

CF: Conventional Fractionation; HS: Hypofractionated Schedule; ILC: infiltrating lobular carcinoma; IDC: infiltrating ductal carcinoma; NA: not available; NS: not significant $(P>0.05)$.

and grade G3 as confluent moist desquamation, other than skin folds, pitting oedema. Grade G0 (no reaction) and Grade G1 (faint reaction) were considered in a common category as concerns the statistical evaluation of the results.

\section{Dosimetry data collection}

Our analysis took origin from the empirical observation of the occurrence of G3 skin reactions in unexpected patients who did not show clinically detectable features predicting adverse effects. 
Revaluating the treatment plans of these patients we observed inhomogeneities of dose distribution which were related to the higher skin toxicities appearing before or after the end of treatment. Following this observation, treatment plans were retrieved and revaluated and a strong correlation was found between areas close to the skin surface, with an inhomogeneity $>107 \%$ of the prescribed dose, and the desquamation areas as described in the clinical records. This quantitative dosevolume analysis was performed in 200 patients representing more than $60 \%$ of all the patients with any toxicity grade. We contoured, on each scan from the CT planning within and outside the target, the Regions of Interest (ROIs) corresponding to the areas receiving a dose in excessive $>107 \%$ of the prescribed one (> 53.5 Gy for CF and > 47.1 Gy for HS) which were named $\mathrm{V}>107$ (cc) (Figure 1). The maximum doses, over $107 \%$ of the prescribed ones, were also recorded. Breast volume was estimated using volumetric measurements of the planning target volume (PTV). Dosimetry data are reported in Table 2.

\section{"In vivo" measurements}

During the first treatment sessions we used the OneDosePlusTM MOSFET based as a dosimetric system for "in vivo" measurements in order to measure the dose actually delivered and to test the entire treatment procedure. Each MOSFET dosimeter was attached to the patient's skin with its build-up cap area at the projection of the isocenter and as perpendicular as possible to the beam central axis. These doses were compared with those calculated with Precise Plan. For each patient, the measurements were performed using one MOSFET for each field of the treatment plan (both medial and lateral fields). We calculated an Action Threshold (AT), defined
Table 2 Treatment and dosimetric characteristics in 200 patients whose plans were revaluated

\begin{tabular}{|c|c|}
\hline CF: 79/141 (56\%) & HF: $121 / 198(61,1 \%)$ \\
\hline PTV (Gy) & PTV (Gy) \\
\hline Mean Dose: 50,17 & Mean Dose: 44,16 \\
\hline Median Dose: 50,30 & Median Dose: 44,39 \\
\hline$V>107 \%(\mathrm{cc})$ & $V>107 \%(c c)$ \\
\hline Mean Volume 10 & Mean Volume 5.7 \\
\hline Median Volume 9 & Median Volume 3 \\
\hline
\end{tabular}

Mean Maximum Dose (Gy) 55,84 Mean Maximum Dose(Gy) 49,20 CF: Conventional Fractionation; HS: Hypofractionated Schedule.

as the maximum acceptable discrepancy between the dose measured with the detector and the dose calculated with the TPS for each single field from phantom data [12]. The AT was $\pm 5 \%$ within 2 Standard Deviations.

\section{Statistical analysis}

The $\chi^{2}$ and Mann-Whitney tests were used to compare acute skin toxicity between different sample groups and to analyze associations between acute toxicity, dosimetric parameters and clinical characteristics. Multivariate analysis to independently predict the risk of acute skin toxicity development was performed using binary logistic regression. Statistical significance was assumed at $\mathrm{p}<$ 0.05; data were processed using the Statistical Package of Social Sciences (SPSS) Version 17.0.

\section{Results}

Acute toxicity rates (Table 3) were found to be higher among the patients undergoing CF (81.6\%) with respect to those treated with the moderate HS (62.6\%) and the difference, which is statistically significant ( $<0.001)$, is not surprising.
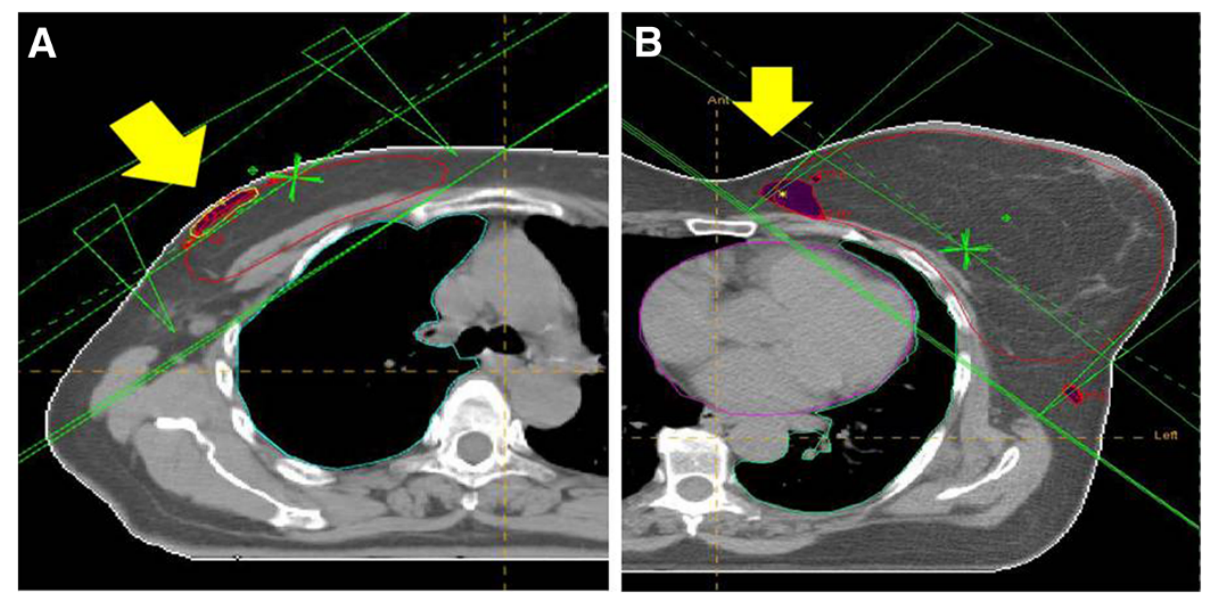

Figure 1 Dose distribution in different breasts with and without moist desquamation. 1A Treatment plan of a patient developing moist dry desquamation of the external upper quadrant. The $\mathrm{V}>107 \%$ is located close to the skin surface (yellow arrow). 1B - Treatment plan of a patient with large breast not developing skin toxicity. The $V>107 \%$ is located deeply in the breast parenchyma (yellow arrow). 
Table 3 Frequency of any grade of acute skin toxicity between the two groups of patients

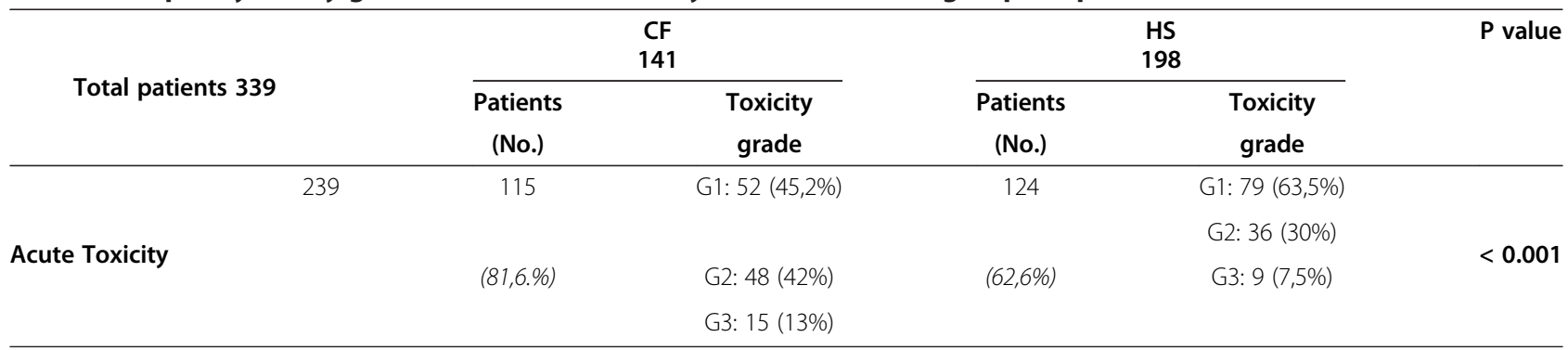

In particular G2 and G3 acute skin toxicities were registered in $42 \%(48 / 115)$ and $13 \%(15 / 115)$ among the patients who underwent irradiation with $\mathrm{CF}$ and in $30 \%$ $(36 / 124)$ and $7.5 \%(9 / 124)$ in the HS group respectively. The onset of the peak skin toxicity, among the patients undergoing conventional fractionation, appeared during the last week of treatment (between session number 20 and 25) while, on the contrary, it appeared immediately after the end of treatment among those undergoing hypofractionated irradiation (around session number 16). For this reason the treatment was interrupted in 5 patients only and all of them belonged to the CF group, but in none of those undergoing HF treatment. Eighty percent of skin reactions occurred at the level of the inframammary fold and the remaining ones in the upper quadrants-axilla. G2-G3 skin reactions were always in close proximity of an inhomogeneity of dose distribution which was located under the skin surface. No skin reaction was diagnosed in all of the patients in whom dose inhomogeneity were deep in the breast tissue distant from the skin.

Systemic treatments and patient and treatment related factors of all of the 339 patients have been evaluated in a univariate analysis (Table 4). Only age and fractionation were found to be statistically significant as concerns the occurrence of acute skin reaction $(\mathrm{p}<0.001)$ while

Table 4 Univariate analysis: predictive factors for G1-G2G3 radiation-induced skin reactions (339 patients)

\begin{tabular}{lc}
\hline Variables & $\boldsymbol{p}$ value \\
\hline Chemotherapy & 0.806 \\
(yes vs no) & \\
Hormone Therapy & 0.665 \\
(yes vs no) & $<0.001$ \\
Age & \\
( $\leq$ average vs > average) & 0.072 \\
Breast Volume & \\
( $\leq$ average vs > average) & $<0.001$ \\
Fractionation Schedule & \\
(CF vs HS) &
\end{tabular}

CF: Conventional Fractionation; HS: Hypofractionated Schedule. systemic treatments and volume of the breast did not show any influence on the occurrence of acute adverse effects $(\mathrm{p}=0.80, \mathrm{p}=0.66$ and $\mathrm{p}=0.072$ respectively for chemotherapy, hormone treatment, breast volume). In our analysis other clinical factors such as smoking, hypertension, diabetes, were not significantly correlated with the development of acute skin reaction. No topic treatment was prescribed in any of these patients to prevent or modify skin reaction.

The treatment plans of 200 patients, including approximately $60 \%$ of the patients belonging to the HS and CF groups, were retrieved and revaluated and volumes receiving more than $107 \%(\mathrm{~V}>107 \%)$ of the prescribed dose were defined in each single case. Half of these patients showed no skin reaction (G0) or a very faint reaction (G1), while the remaining belonged to the $\mathrm{G} 2$ - G3 groups.

At the univariate analysis, as summarised in Table 5, younger age at diagnosis $(\mathrm{p}=0.004)$, larger breast volume $(\mathrm{p}=0.011)$, conventional fractionation $(\mathrm{p}<0.001)$ and $\mathrm{V}>107 \%$ were related to an increased risk of G2 G3 skin reactions. Indeed, patients with no skin reaction (G0) or faint limited erythema were found to have a smaller $\mathrm{V}>107 \%$ (3.9 cc $\pm 5.6 \mathrm{SD})$ in comparison to those who presented a true skin reaction (G2 - G3) whose $\mathrm{V}>107 \%$ was, in average, $10.9 \mathrm{cc} \pm 8.7 \mathrm{SD}$. The difference is statistically significant $(\mathrm{p}<0.001)$. No statistically significant difference was highlighted, on the contrary, for the maximum doses recorded in the ROIs.

At the multivariate analysis (Table 5) the only variable retaining significance was $\mathrm{V}>107 \%(\mathrm{p}<0.001)$ while fractionation only showed a tendency towards significance in favour of HS vs CF. The RR for patients with $\mathrm{V}>107 \%$ above the median value was 6 times higher than those with $\mathrm{V}>107 \%$ below the median value.

Figure 2 shows the number of patients with a volume receiving more than $\mathrm{V}>107 \%$ by grade of skin reaction: hot spots are more represented among G2 - G3 patients. Plotting the data by the volumes receiving more than $\mathrm{V}>107 \%$ for the HF and CF respectively we obtain a more detailed description of these results (Figure 3): patients with higher values of $\mathrm{V}>107 \%$ are evidently more represented among those showing G2 and G3 skin reactions. 
Table 5 Univariate and multivariate analysis for G2-G3 radiation induced skin reactions in 200 patients

\begin{tabular}{|c|c|c|c|c|}
\hline \multirow{2}{*}{ Variables } & \multicolumn{2}{|c|}{ Univariate analysis } & \multicolumn{2}{|c|}{ Multivariate analysis } \\
\hline & & $P$ & Odds ratio $(95 \% \mathrm{Cl})$ & $\mathbf{P}$ \\
\hline Chemotherapy & Yes vs No & 0.054 & $1.137(0.531-2.433)$ & 0.741 \\
\hline Hormone Therapy & Yes vs No & 0.401 & $1.230(0.547-2.765)$ & 0.616 \\
\hline Fractionation Schedule & CF vs HS & $<0.001$ & $2.045(0.996-4.197)$ & 0.51 \\
\hline$V>107 \%$ & Mean \pm SD & $<0.001$ & $6.335(3.192-12.577)$ & $<0.001$ \\
\hline Age & Mean \pm SD & 0.004 & $0.973(0.943-1.005)$ & 0.101 \\
\hline Breast Volume & Mean \pm SD & 0.011 & $1.001(1.000-1.002)$ & 0.076 \\
\hline
\end{tabular}

Cl: confidence intervals; SD: standard deviation. CF: Conventional Fractionation; HS: Hypofractionated Schedule.

In this preliminary experience an average value distinguishing between high and low risk of developing mild to moderate or severe skin reaction has been found to be $3 \mathrm{cc}$ for the HF patients and $9 \mathrm{cc}$ for the $\mathrm{CF}$ ones (Figure 3). Volumes, in cubic centimetres, receiving more than $107 \%$ of the prescribed dose are larger among the CF group (mean $10 \mathrm{cc}$ and median $9 \mathrm{cc}$ ) than among the HF patients (mean 5,7 cc and median $3 \mathrm{cc}$ ) (Table 2).

\section{Discussion}

Acute toxicity after treatment for breast cancer is an issue which has been recently addressed in the literature $[3,4]$ and which deserves consideration as severe skin toxicity can lead to temporary or permanent cessation of treatment causing pain and maybe permanent skin changes. After conservative surgery different fractionation schemes have been introduced in the treatment of breast cancer patients. With 5 and 10 years of follow-up the efficacy and cosmetic results of non conventional fractionation schemes have been proven, in comparison to the conventional ones, resulting in improved patient convenience and decreased resource utilization [13-15]. Patients included in the aforementioned randomized trials were predominantly treated with two dimensional planning techniques, non-uniform use of inhomogeneity corrections, and dose calculations limited to the central axis. In the past decade there have been substantial shifts in patterns of practice such that the 3D-CRT and IMRT became widespread and have been proven beneficial in improving dose homogeneity and reducing acute skin toxicity in randomized trials $[16,17]$. In a recent study Dorn and coll. have specifically examined dosimetric parameters and acute toxicity in patients with separation > $25 \mathrm{~cm}$ or large breast volume treated with HF. Their rates of acute toxicity (8.7\%) compare favourably with those reported in other series of patients as well as with

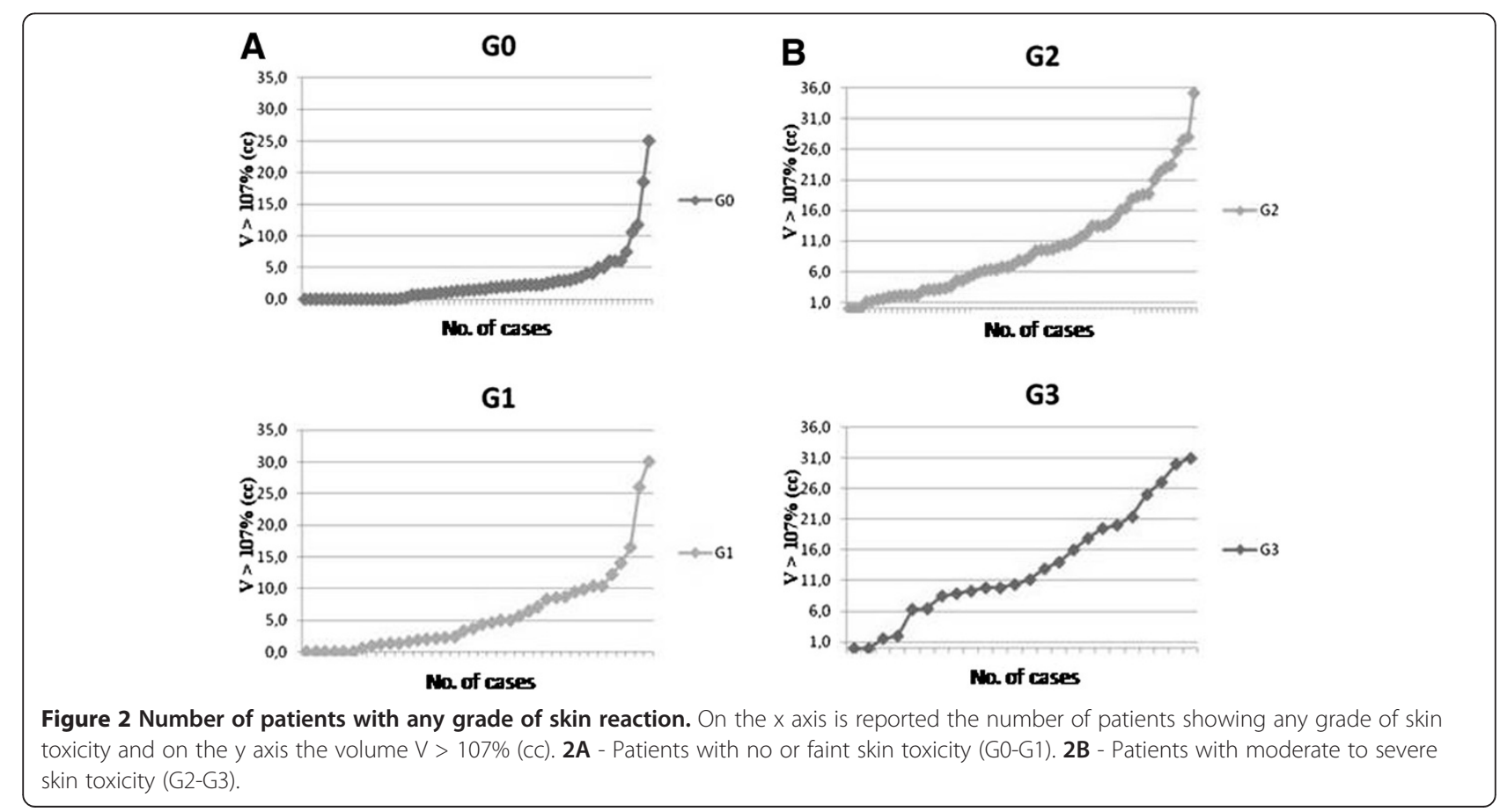



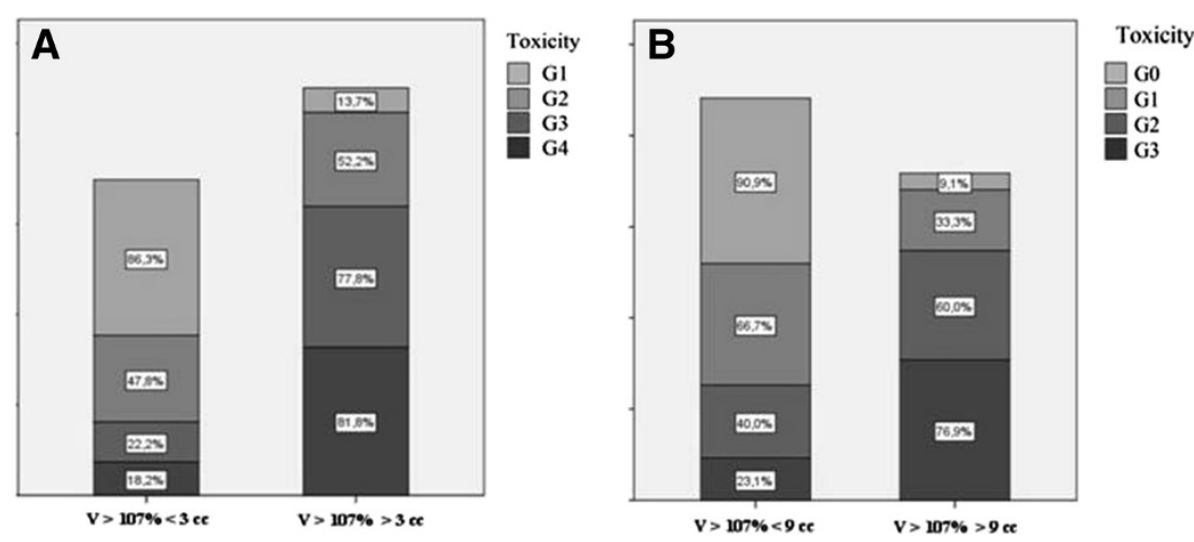

Figure 3 Distribution of acute skin reactions in patients undergoing different fractionation and median $V>107$ cut-off value.

$\mathbf{3 A}$ - Hypofractionation group where most of patients with G0- G1 reactions belong to the median cut-off $\mathrm{V}>107 \%$ value $<3 \mathrm{cc}$. $3 \mathbf{B}-\mathrm{Conventional}$ fractionation group where most of patients with G0- G1 reactions belong to the median cut-off $V>107 \%$ value $<9 \mathrm{cc}$.

the data in our series (G3 13\% and 7.5\% respectively in the CF and HF patients) [8].

In our series (339 patients) the only factors associated with any grade of skin toxicity at a univariate analysis were age at diagnosis and fractionation. Breast volume, systemic treatments and other patient related factors did not show any influence on the occurrence of skin toxicity.

As concerns breast volume as a relevant factor related to skin toxicity contradictory data are available in the literature. Recently two papers $[18,19]$ reach opposite conclusions. Corbin et al. [18] state that among obese and large breasted women $\left(>1500 \mathrm{~cm}^{3}\right)$, in their experience, there was no increase in acute skin toxicity in the group undergoing hypofractionated radiation therapy. On the contrary Kraus-Tiefenbacher et al. [19] state that one of the factors associated with higher grade skin toxicity was, in their experience, the presence of larger breast volumes (range 402-4283 cc, median 946,9 cc). One possible explanation for these discrepancies may be that different criteria have been used to define what is considered "a large breast". Freedman et al. [20] found a positive correlation between breast size and skin toxicity in larger breast volumes defined as $>$ cup D. Vicini et al. [21] found that patients with breast volume $>1600 \mathrm{cc}$ had more acute skin toxicity compared to those with smaller breast volumes (<1000 cc). Another report [22] showed no G3 RTOG acute effect with breast volumes < 975 cc while patients with breast volumes greater then 1600 cc developed 59\% RTOG G2 and 3\% G3 erythema. As in our evaluation they measured breast volume in analogy to our method (manually contouring of breast target volume). The average breast volumes among our patients are smaller (718.7 cc, range between $188.6 \mathrm{cc}$ and $2036.7 \mathrm{cc}$ ) than those reported in the previous papers. Even as concerns the role of systemic treatments before external beam radiation therapy on skin toxicity the data in the literature are contradictory. There are a few studies where a significant correlation between chemotherapy and increased skin toxicity was documented $[21,22]$. Different results have on the contrary been published [23,24] showing a trend to increase higher grade skin toxicity after chemotherapy.

Our statistical analysis was performed on 200 patients whose 3D-CRT were retrieved and revaluated to better define site and size of homogeneities of dose distribution and its relation with the site of the skin damage. We decided to revaluate the entire 3D plan, instead of relying only on the DVHs of the single patient which does not allow to locate the site of the dose inhomogeneities $>107 \%$ which we consider relevant to the development of acute skin toxicity. Among these patients age, type of fractionation (CF vs HS), breast volume and inhomogeneity of dose distribution $(\mathrm{V}>107 \%)$ were statistically significant at the univariate analysis and correlated with skin reaction. On multivariate analysis, on the contrary, there was only an association between the heterogeneity parameter $\mathrm{V}>107 \%$ and skin reaction which is not unexpected.

In two randomized trials $[25,26]$ comparing IMRT to two-dimensional breast planning, improved homogeneity translated into reductions in acute toxicity supporting the need that an accurate evaluation of dose homogeneity, before treatment delivery, may reduce acute severe skin reactions.

IMRT may obtain a better dose distribution and a reduction of dose inhomogeneities, but it is more time consuming as concerns planning and delivery and it is, of course, more expensive. As the number of patients deserving a more complex treatment is limited to those at risk for severe skin damage, who are approximately less than $10 \%$ of all of the patients undergoing postoperative irradiation for breast cancer, IMRT should be 
considered after accurate examination of 3D dose distribution showing dose inhomogeneities greater than 107\% of the prescribed dose.

As concerns age we underline that, at least in our series, it is unrelated to skin toxicity in spite of the significance obtained at univariate analysis $(\mathrm{p}=0.001)$. At the beginning of our experience we selected, in fact, older patients to undergo treatment with the HF schedule and this selection has probably introduced a bias in the analysis.

Dosimetric analyses in the aforementioned randomised trials [13-15] were mainly performed at the central axis and therefore no information were available on the offaxis target volume and on site and size of hot spots and dose inhomogeneities. In this analysis off-axis heterogeneity was evaluated on the retrieved and revaluated 3-D plans allowing a clear definition of the site and size of the hot spots. Inhomogeneities were found to be significant and on multivariate analysis they were found to be the only factor retaining statistical significance [OR: 6.3 (95\% CI: 3.192 - 12.577); $\mathrm{p}<0.001]$. The Odd Ratio for $\mathrm{V}>107 \%$ is six times higher than that calculated for systemic therapies, age and breast volume, and three times higher than that related to fractionation supporting the strong relation between dose inhomogeneity and acute severe skin reaction.

The retrieval of the treatment plans allowed, moreover, an evaluation of the relation between the site of the hot spots and the occurrence of skin reaction. Hot spots were more frequent than skin reactions due to the fact that only inhomogeneities close to the skin surface were responsible of skin reactions which were consistent with the description of the site and size of moist desquamation reported in the clinical records. Hot spots deep seated in the breast parenchyma may probably contribute to the occurrence of different types of acute or late toxicities, but do not contribute, in our experience, to severe skin acute damage.

In our series skin toxicity appeared always immediately before or concomitant to the end of the treatment on the entire breast and always before the boost irradiation of the tumor bed excluding any role or responsibility of the boost as concerns the occurrence of the reaction.

Data from the literature and from our series show that dose inhomogeneities may be responsible for acute skin damage while the role of different patient or tumor related factors, other than breast volume, are not common to all of the reported experiences in the literature. Recently the attention has been focused on the fact that mismatch repair mechanisms may be involved in cellular response to RT and genetic polymorphisms [27] may be candidates for predicting acute radiosensitivity and we believe that further studies evaluating this hypothesis may contribute to a better comprehension of the steps leading to the occurrence of severe acute skin reactions.

\section{Conclusions}

In conclusion:

1. The proportion of patients expected to experience high grade skin toxicity is on the order of $10-15 \%$ among HF patients and such rates compare favourably with those reported in our series (G3 13\% and $7.5 \%$ respectively in the CF and HF patients) supporting the use of HF in the treatment of patients after BCS without any risk of increasing acute skin damage;

2. HF after BCS is safe and feasible and a shorter course of treatment in a broader range of patients may improve patient convenience and decrease resource utilization;

3. with the limits of a retrospective study our results suggests that dose inhomogeneties $(\mathrm{V}>107 \%)$ have a significant impact on the occurrence of severe skin reactions as pointed out by Chen and coll. [7] too who demonstrated that a larger volume receiving > 53.9 Gy, within PTV (PTV - V107\%), was a significant predictor of RT- induced skin toxicity;

4. deep seated dose inhomogeneities, which do not correlate with skin reaction, deserve particular attention to detect other types of side effects which have not yet been investigated and reported in the aforementioned randomized trials;

5. increasing interest is arising around the possibility that genetic polymorphisms may be candidates for predicting acute radiosensitivity and this aspect deserves attention and has to be investigated.

\section{Appendix}

$n$ : total number of fractions

$d$ : size of fractions in Gy

$T$ : overall time of treatment (days, with first day as D0)

$T k$ : onset (kick-off) time of repopulation in the tissue of interest: 21 days

$T p$ : potential doubling time of cancer repopulating cells: 3 days

$\alpha$ : radiosensitivity coefficient of non-recoverable damage: 0.35

\section{Competing interests}

The authors have no financial disclosures or conflicts of interest to report.

\section{Authors' contributions}

Each of the co-authors has made important contributions to this manuscript. In particular: GT reviewed and analyzed the data, performed statistical analysis, created the figures, and drafted the manuscript. LDM reviewed and analyzed the data, performed statistical analysis, created the figures, drafted the manuscript and participated in the design of study. MDF participated in the design of study, interpretation and analysis of data. GT, LDM, RB, SC, DdC, DF, GI, DJ, PM, AM, EP, ST, BT were responsible in collection of dosimetric and clinical data. RS provided significant intellectual contribution, drafted and reviewed the manuscript. All authors read and approved the final manuscript. 
Received: 15 November 2012 Accepted: 10 April 2013

Published: 7 May 2013

\section{References}

1. Clarke M, Collins R, Darby S, Darby S, Davies C, Elphinstone P, Evans E, Godwin J, Gray R, Hicks C, James S, Mackinnon E, McGale P, McHugh T, Peto R, Taylor C, Wang Y: Early Breast cancer Trialists' Collaborative Group (EBCTCG). Effects of radiotherapy and of differences in the extent of surgery for early breast cancer on local recurrence and 15-year survival: an overview of the randomized trials. Lancet 2005, 366:2087-2106.

2. Matzinger $O$, Heimsoth I, Poortmans $P$, Collette L, Struikmans H, Van Den Bogaert W, Fourquet A, Bartelink H, Ataman F, Gulyban A, Pierart M, Van Tienhoven G: EORTC Radiation Oncology and Breast Cancer Groups. Toxicity at three years with and without irradiation of the internal mammary and medial supraclavicular lymph node chain in stage I to III breast Cancer (EORTC trial 22922/10925). Acta Oncol 2010, 49:24-34.

3. Pignol JP, Olivotto I, Rakovitch E, Gardner S, Sixel K, Beckham W, Vu TT, Truong P, Ackerman I, Paszat L: A Multicenter randomised trial of breast intensity-modulated radiation therapy to reduce acute radiation dermatitis. J Clin Oncol 2008, 26:2085-2092.

4. Morganti AG, Cilla S, Valentini V, Digesù C, Macchia G, Deodato F, Ferrandina G, Cece MG, Cirocco M, Garganese G, Di Lullo L, Traficante D, Scarabeo F, Panunzi S, De Gaetano A, Sallustio G, Cellini N, Sofo L, Piermattei A, Scambia G: Phase I-II studies on accelerated IMRT in breast carcinoma: technical comparison and acute toxicity in 332 patients. Radiother Oncol 2009, 90:86-92.

5. Croog VJ, Wu AJ, McCormick B, Beal KP: Accelerated whole breast irradiation with intensity-modulated radiotherapy to the prone breast. Int J Radia Oncol Biol Phys 2009, 73:88-93.

6. Bucholoz TA, Gurgoze E, Bice WS, Prestidge BR: Dosimetric analysis of intact breast irradiation in off-axis planes. Int J Radia Oncol Biol Phys 1997, 39:261-67.

7. Chen MF, Chen WC, Lai CH, Hung CH, Liu KC, Cheng YH: Predective factors of radiation-induced skin toxicity in breast cancer patients. BMC Cancer 2010, 10:508.

8. Dorn PL, Corbin KS, Al-HAllaq H, Hasan Y, Chmura SJ: Feasibility and acute toxicity of hypofractionated radiation in large-breasted patients. Int $J$ Radiat Oncol Biol Phys 2012 May 1, 83(1):79-83.

9. Fowler JF: 21 years of Biologically Effective Dose. $\mathrm{Br} J$ Radiol 2010, 83:554-568.

10. ICRU: Prescribing, recording, and reporting photon beam therapy. In ICRU report. Volume 50. Bethesda: International Commission on Radiation Units and Measurements; 1993.

11. ICRU: Prescribing, recording, and reporting photon beam therapy (supplement to ICRU report 50). In ICRU Report. Volume 62. Bethesda: International Commission on Radiation Units and Measurements; 1999.

12. Falco MD, D'Andrea M, Lo Bosco A, Rebuzzi M, Ponti E, Tolu B, Tortorelli G, Barbarino R, Di Murro L, Santoni R: Is the in vivo dosimetry with the OneDosePlusTM system able to detect intra-fraction motion? A retrospective analysis of in vivo data from breast and prostate patients. Radiat Oncol 2012, 7:97.

13. Whelan TJ, Pignol JP, Levine MN, Julian JA, Mackenzie R, Parpia S, Shelley W, Grimard L, Bowen J, Lukka H, Perera F, Fyles A, Schneider K, Gulavita S, Freeman C: Long-term results of hypofractionated radiation therapy for breast cancer. N England J Med 2010, 362:513-520.

14. Bentzen SM, Agrawal RK, Aird EG, Barrett JM, Barrett-Lee PJ, Bliss JM, Brown J, Dewar JA, Dobbs HJ, Haviland JS, Hoskin PJ, Hopwood P, Lawton PA, Magee BJ, Mills J, Morgan DA, Owen JR, Simmons S, Sumo G, Sydenham MA, Venables K, Yarnold JR: The UK Standardization of Breast Radiotherapy (START) trial A of radiotherapy hypofractionation for treatment of early breast cancer: $A$ randomised trial. Lancet Oncol 2008, 9:331-341.

15. Bentzen SM, Agrawal RK, Aird EG, Barrett JM, Barrett-Lee PJ, Bliss JM, Brown J, Dewar JA, Dobbs HJ, Haviland JS, Hoskin PJ, Hopwood P, Lawton PA, Magee BJ, Mills J, Morgan DA, Owen JR, Simmons S, Sumo G, Sydenham MA, Venables K, Yarnold JR: The UK Standardisation of Breast Radiotherapy (START) trial B of radiotherapy hypofractionation for treatment of early breast cancer: A randomised trial. Lancet 2008 371:1098-1107.

16. White JR, Khalid N, Tao ML, Pierce $L$, DeRobertis A, Crozier C, Owen JB, Wilson JF: QRRO 2007 Practice Survey Documents Dramatic Technical Changes in How Radiotherapy for operable Breast Cancer is Delivered. Int J Radiat Oncol Biol Phys 2010, 78:S4.
17. Dwyer P, Hickey B, Burmeister E, Burmeister B: Hypofractionated wholebreast radiotherapy: Impact on departmental waiting times an cost. J Med Imaging Radiat Oncol 2010, 54:229-234.

18. Corbin KS, Dorn PL, Jain SK, Al-Hallaq HA, Hasan Y, Chmura SJ: Hypofractionated Radiotherapy Does Not Increase Acute Toxicity in Large-Breasted Women: Results From a Prospectively Collected Series. Am J Clin Oncol 2013. Epub ahead of print.

19. Kraus-Tiefenbacher U, Sfintizky A, Welzel G, Simeonova A, Sperk E, Siebenlist K, Mai S, Wenz F: Factors of influence on acute skin toxicity of breast cancer patients treated with standard external beam radiotherapy (EBRT) after breast conserving surgery (BCS). Radiat Oncol 2012, 7(1):217. Epub ahead of print.

20. Freedman GM, Anderson PR, Li J, Eisenberg DF, Hanlon AL, Wang L, Nicolaou N: Intensity modulated radiation therapy (IMRT) decreases acute skin toxicity for women receiving radiation for breast cancer. Am J Clin Oncol 2006 Feb, 29(1):66-70.

21. Vicini FA, Sharpe M, Kestin L, Martinez A, Mitchell CK, Wallace MF, Matter R, Wong J: Optimizing breast cancer treatment efficacy with intensitymodulated radiotherapy. Int J Radiat Oncol Biol Phys 2002, 54(5):1336-44.

22. Harsolia A, Kestin L, Grills I, Wallace M, Jolly S, Jones C, Lala M, Martinez A, Schell S, Vicini FA: Intensity-modulated radiotherapy results in significant decrease in clinical toxicities compared with conventional wedge-based breast radiotherapy. Int J Radiat Oncol Biol Phys 2007, 68(5):1375-80. Epub 2007 Jun 4.

23. Back M, Guerrieri M, Wratten C, Steigler A: Impact of radiation therapy on acute toxicity in breast conservation therapy for early breast cancer. Clin Oncol (R Coll Radiol) 2004, 16(1):12-6.

24. Taylor ME, Perez CA, Halverson KJ, Kuske RR, Philpott GW, Garcia DM, Mortimer JE, Myerson RJ, Radford D, Rush C: Factors influencing cosmetic results after conservation therapy for breast cancer. Int J Radiat Oncol Biol Phys 1995, 31(4):753-64.

25. Donovan E, Bleakley N, Denholm E, Evans P, Gothard L, Hanson J, Peckitt C, Reise S, Ross G, Sharp G, Symonds-Tayler R, Tait D, Yarnold J: Breast Technology Group. Randomised trial of standard 2D radiotherapy (RT) versus intensity modulated radiotherapy (IMRT) in patients prescribed breast radiotherapy. Radiother Oncol 2007, 82:254-264.

26. Barnett GC, Wilkinson J, Moody AM, Wilson CB, Sharma R, Klager S, Hoole ACF, Twyman N, Burnet NG, Coles CE: A randomized controlled trial of forward-planned radiotherapy (IMRT) for early breast cancer: Baseline characterisics and dosimetry results.

27. Mangoni M, Bisanzi S, Carozzi F, Sani C, Biti G, Livi L, Barletta E, Costantini AS, Gorini G: Association between genetic polymorphisms in the XRCC1, XRCC3, XPD, GSTM1, GSTT1, MSH2, MLH1, MSH3, and MGMT genes and radiosensitivity in breast cancer patients. Int J Radiat Oncol Biol Phys 2011, 81:52-58.

\section{doi:10.1186/1471-2407-13-230}

Cite this article as: Tortorelli et al:: Standard or hypofractionated radiotherapy in the postoperative treatment of breast cancer: a retrospective analysis of acute skin toxicity and dose inhomogeneities. BMC Cancer 2013 13:230.

\section{Submit your next manuscript to BioMed Central and take full advantage of:}

- Convenient online submission

- Thorough peer review

- No space constraints or color figure charges

- Immediate publication on acceptance

- Inclusion in PubMed, CAS, Scopus and Google Scholar

- Research which is freely available for redistribution 